\title{
Predicting Monovalent Ion Correlation Effects in Nucleic Acids
}

\author{
Li-Zhen Sun, ${ }^{\dagger \ddagger}$ Yuanzhe Zhou, ${ }^{\ddagger}$ and Shi-Jie Chen* $*$. \\ ${ }^{\dagger}$ Department of Applied Physics, Zhejiang University of Technology, Hangzhou 310023, China \\ ${ }^{\ddagger}$ Department of Physics, Department of Biochemistry, and Informatics Institute, University of Missouri, Columbia, Missouri 65211, \\ United States
}

\section{Supporting Information}

ABSTRACT: Ion correlation and fluctuation can play a potentially significant role in metal ion-nucleic acid interactions. Previous studies have focused on the effects for multivalent cations. However, the correlation and fluctuation effects can be important also for monovalent cations around the nucleic acid surface. Here, we report a model, gMCTBI, that can explicitly treat discrete distributions of both monovalent and multivalent cations and can account for the correlation and fluctuation effects for the cations in the solution. The gMCTBI model enables investigation of the global ion binding properties as well as the detailed discrete
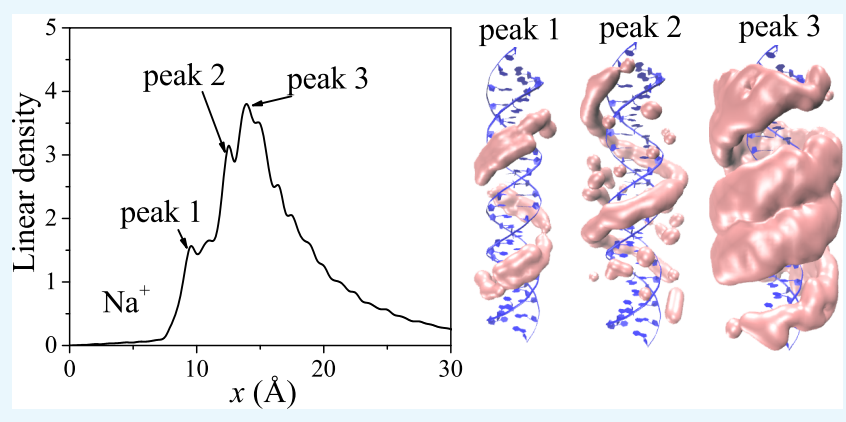
Accounting for the io correlation effect for monovalent ions can lead to more accurate predictions, especially in a mixed monovalent and multivalent salt solution, for the number and location of the bound ions. Furthermore, although the monovalent ion-mediated correlation does not show a significant effect on the number of bound ions, the correlation may enhance the accumulation of monovalent ions near the nucleic acid surface and hence affect the ion distribution. The study further reveals novel ion correlation-induced effects in the competition between the different cations around nucleic acids.

\section{INTRODUCTION}

Nucleic acids (DNAs and RNAs) are highly charged polyanions. The folding of nucleic acids involves metal ion binding, which causes charge neutralization and screening of Coulomb repulsion between backbone charges. ${ }^{1}$ Indeed, electrostatic interactions make significant contributions to nucleic acid folding stability ${ }^{2-6}$ and conformational equilibrium and transitions. ${ }^{7}$ Moreover, metal ions are essential for many biochemical reactions such as catalytic reactions of ribozymes. $^{8-13}$ To understand the nucleic acid structure and function, a computational model for metal ion effects is highly needed.

In general, metal ions around the nucleic acids can be classified into site-specific bound (SSB) ions ${ }^{14}$ and nonspecific bound (NSB) ions. ${ }^{15}$ SSB ions are partially or fully dehydrated and trapped (chelated) at specific sites or regions such as pockets in three-dimensional (3D) structures, ${ }^{16}$ whereas NSB ions are often hydrated and form an "ion cloud" (or "ion atmosphere") ${ }^{17-19}$ around the nucleic acid. SSB ions can interact directly with the nucleic acid ${ }^{20}$ and participate in nucleic acid biochemical reactions. ${ }^{8-12}$ Physical properties of SSB ions, including ion-nucleic acid ${ }^{21}$ and ion-ion interactions, ${ }^{22,23}$ can be probed by X-ray and NMR measurements. Theoretically, the binding sites of SSB ions can be predicted by a variety of methods such as the knowledge-based MetalionRNA model. ${ }^{24}$

The interactions between (the large number of) NSB ions and the nucleic acid provide a significant stabilizing force for nucleic acid folding. To understand the ion effects on nucleic acid stability, it is highly desirable to understand the number and the distribution of NSB ions. A particularly important property of NSB ions is the number of excess NSB ions $(\Gamma)$ in the ion atmosphere. The number of excess NSB ions $\Gamma$ is the number of excess ions above the number expected based on the bulk concentration. In experiments, $\Gamma$ can be determined using various "ion count" methods, such as buffer equilibration and atomic emission spectroscopy, ${ }^{17,19}$ anomalous small-angle $\mathrm{X}$-ray scattering, ${ }^{25}$ and dye indicator. ${ }^{26-29}$ However, experimental determination of further details about the NSB ion atmosphere such as the ion distribution and ion-induced electrostatic free energy changes remains a challenge. ${ }^{30} \mathrm{We}$ need theoretical models to predict ion-nucleic acid interactions and ion binding properties.

Many theories and computational models such as counterion condensation (CC) theory $^{31-33}$ and nonlinear PoissonBoltzmann (NLPB) theory ${ }^{34-40}$ have been developed for ionnucleic acid interactions. These theories and models have led to important insights into ion effects on nucleic acid structures and stabilities. However, most of these theories rely on the mean-field approximation by neglecting the ion coupling (correlation) effect. In an ionic solution, ions can be correlated due to volume exclusion and Coulombic interactions. ${ }^{30}$ Such a

Received: June 9, 2019

Accepted: July 18, 2019

Published: August 5, 2019 
correlation can be particularly strong for ions distributed in the close vicinity of the nucleic acid surface, where ion concentrations can be high. Previous experimental and theoretical results have suggested that the correlation effect could be important for multivalent ions. ${ }^{17,30,41,42}$

According to the ion correlation strength, the NSB ions can be further classified into two types: the diffusely bound (DB) ions for the weakly correlated ions ${ }^{15}$ and the tightly bound (TB) ions for the strongly correlated ions. ${ }^{42}$ Although both the $\mathrm{DB}$ and the TB ions belong to the NSB ions, they have different binding properties. The $\mathrm{DB}$ ions move around the nucleic acid diffusely in the region separated from the nucleic acid surface by a distance, ${ }^{43}$ whereas the TB ions are clustered around the nucleic acid surface to form a thin layer of high local concentration. ${ }^{42}$ The strong ion correlation lowers the mobility of the TB ions. ${ }^{30}$ It is important to note that unlike SSB ions, TB ions are assumed to be fully hydrated and do not form direct chelation with the nucleic acid. Experiment-NLPB comparisons ${ }^{17,19}$ showed that the NLPB model may provide reliable predictions for the weakly correlated ions (DB ions) but could also underestimate the ion binding effects for the strongly correlated ions (TB ions).

DB ions can be treated as a continuous fluid with the meanfield theory. However, TB ions, which are strongly correlated, need to be treated at the level of discrete many-particle distributions to account for the coupling between the different ions. Molecular dynamics (MD) simulations are able to fully account for the correlation effect in ion-nucleic acid interactions, $^{44}$ such as $\mathrm{Mg}^{2+}$ binding to the SAM-I riboswitch, ${ }^{45}$ 5S rRNA Loop E Motif, ${ }^{46}$ and ribozyme. ${ }^{47}$ Monte Carlo (MC) simulations can also sample the correlated $\mathrm{Mg}^{2+}$ distributions around the nucleic acids. ${ }^{48-50}$ The sampling of the discrete ion distributions intrinsically reveals the ion fluctuation effect, which can be important for RNA folding. ${ }^{30,42}$

The previous emphasis on the ion correlation effect has been nearly exclusively focused on the multivalent ions such as $\mathrm{Mg}^{2+}$ ions. Successful attempts have been made to address the correlation for multivalent ions by modifying the $\mathrm{NLPB}^{51-53}$ or the CC models. ${ }^{54}$ However, recent experimental evidence indicated that monovalent ions may also cause ion correlation effects in ion-nucleic acid interactions. ${ }^{19,55,56} \mathrm{MD}$ simulations can treat correlation effects with discrete monovalent ions; ${ }^{57-59}$ however, the applications (for monovalent ions or divalent ions) are limited by the long computational time with the explicit treatment for salt, solvent, and atoms in nucleic acids. ${ }^{60}$ To enhance the computational efficiency, the threedimensional reference interaction site model (3D-RISM) was developed to implicitly treat the solvent in simulations by solving the Ornstein and Zernike integral equation. ${ }^{61,62}$ Ions are treated as discrete particles in 3D-RISM. Compared to the NLPB model, the monovalent ion distribution predicted by 3D-RISM is in good agreement with the MD simulation results. $^{61}$ The 3D-RISM model partly relies on MD simulations, so the prediction results can depend on the selected force fields. ${ }^{61}$

The tightly bound ion (TBI) model is a hybrid statistical mechanical model for ion-nucleic acid interactions, which combines the explicit enumeration/sampling of the discrete ion distributions for strongly correlated ions and a mean-field approach for the continuous distributions of weakly correlated ions. The model was originally developed to predict the effect of multivalent ions, particularly, divalent ions, by considering explicitly the ion correlation and fluctuation effects. ${ }^{42}$ In this model, the discrete many-body distributions for the TB (strongly correlated) ions are enumerated and the (correlated) ion-nucleic acid interactions are calculated for each discrete ion distribution. For the DB (weakly correlated) ions, the mean-field NLPB is applied to compute the electrostatic free energy. Extensive comparisons with experimental data have suggested that the TBI model provides improved predictions for the ion effects in nucleic acid folding stabilities. ${ }^{63-71}$ The original TBI model is severely limited by the low computational efficiency due to the time-consuming enumeration method, even for coarse-grained (CG) ion distributions. Recently, to enhance the computation efficiency, MCTBI, ${ }^{72,73}$ a new TBI model, was developed using the Monte Carlo method to sample the TB ion distribution. Compared to the original TBI model, the MCTBI model has two notable advantages: a significant (1000-fold) increase in the computational efficiency and the use of full threedimensional coordinate-based ion distributions.

To account for the correlation and fluctuation effects for the monovalent ions, on the basis of the original MCTBI model, ${ }^{72}$ we here develop a generalized MCTBI-like (gMCTBI) model in this paper. In the original MCTBI model, only multivalent cations such as $\mathrm{Mg}^{2+}$ are classified into the $\mathrm{TB}$ and $\mathrm{DB}$ ions, whereas all of the monovalent cations such as $\mathrm{Na}^{+}$are regarded as DB ions. ${ }^{72,73}$ Therefore, TB ions in the original model include only multivalent cations. In the current gMCTBI model, however, TB ions include not only the (strongly correlated) multivalent ions but also the (strongly correlated) monovalent ions. As a result, the gMCTBI model accounts for three types of ion-ion correlations: monovalent-monovalent, monovalent-multivalent, and multivalent-multivalent. The model has the potential to provide not only improved predictions for the number of bound ions but also more complete and detailed insights into ion binding properties such as the most probable ion distributions. Using gMCTBI, we investigate the ion binding properties around the nucleic acids for $\mathrm{Na}^{+}$and $\mathrm{Na}^{+}$mixed with other monovalent cations (such as $\mathrm{Li}^{+}$and $\left.\mathrm{Cs}^{+}\right)$or divalent cations $\left(\mathrm{Mg}^{2+}\right)$ and validate the theoretical predictions with available experimental data. The model predictions for various systems also reveal new features of ion distributions and ion-nucleic acid interactions.

\section{RESULTS AND DISCUSSION}

To compare our theoretical predictions with the experimental results, we compute the excess number of bound ions $\Gamma_{\alpha}$ for type- $\alpha$ ions; see eqs S4 and S5 in the Supporting Information (SI). ${ }^{74}$ To show the results for the detailed distribution of the bound ions, we also compute the linear density $\rho_{\Gamma}(x)^{45}$ as the spatial distribution function ${ }^{61,62}$ for the excess ions (see eq S6). The physical meaning of the linear density is that $\rho_{\Gamma}(x) \mathrm{d} x$ equals the excess number $\Gamma$ of ions in the region between distances $x$ and $x+\mathrm{d} x$. Here, for DNA helix, $x$ denotes the distance measured from the helix axis. For tRNA ${ }^{\text {Phe }}$, which has a more complicated structure, we define $x$ as the distance to the RNA surface. ${ }^{45}$ The explicit treatment for discrete ion distributions enables us to predict the average and the most probable distributions for TB ions (see eq S7). Furthermore, we compare the results with and without the monovalent ion correlation to assess its effect in ion binding. In this section, we mainly study the ion binding properties around the nucleic acids in various salt solutions: $\mathrm{NaBr}$ (Section 2.1), mixed monovalent salt solution (Section 2.2), and monovalentdivalent mixed salt solution (Section 2.3). In Section 2.4, we 

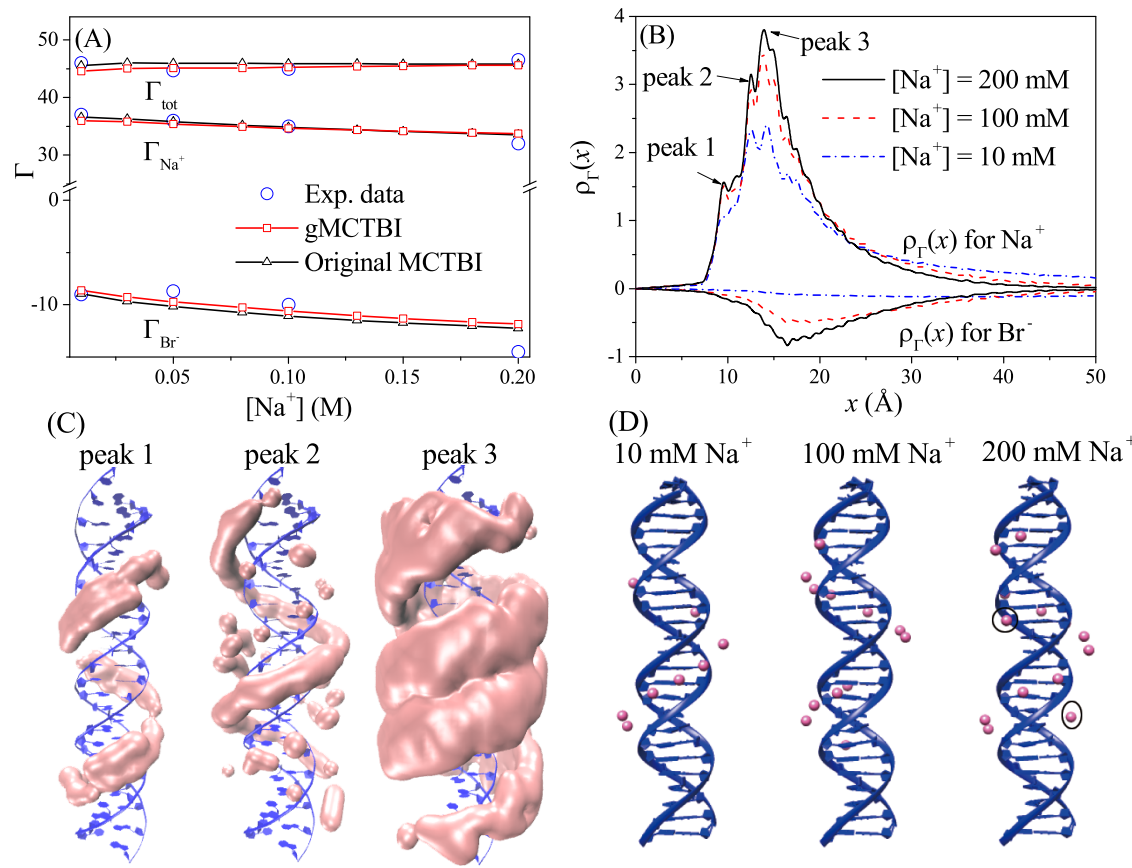

Figure 1. Predictions for ion binding for a 24-bp DNA helix in a $\mathrm{NaBr}$ solution. (A) Excess number of $\mathrm{Na}^{+}$and $\mathrm{Br}^{-}$in various bulk [ $\left.\mathrm{Na}^{+}\right]$. Here, the experimental data (blue circles) is extracted from ref 19. (B) Linear density of the bound $\mathrm{Na}^{+}$and $\mathrm{Br}^{-}$ions predicted by the gMCTBI model for the different $\left[\mathrm{Na}^{+}\right]$. (C) Predicted TB Na${ }^{+}$-ion average distributions corresponding to the three peaks in (B). (D) Most probable distributions of the TB $\mathrm{Na}^{+}$ions (purple balls) at $\left[\mathrm{Na}^{+}\right]=10,100$, and $200 \mathrm{mM}$. To show the ion distributions, we use VMD and Chimera to show the (C) average and the (D) most probable distributions, respectively.

will predict the detailed ion binding properties to show the importance of the monovalent ion correlation effects.

2.1. Binding Properties of $\mathrm{Na}^{+}$around B-DNA. We first investigate the ion binding properties for a 24-bp B-DNA helix in a $\mathrm{NaBr}$ solution. Figure $1 \mathrm{~A}$ shows the results for the excess (depletion) number of $\mathrm{Na}^{+}\left(\mathrm{Br}^{-}\right)$ions predicted from the original MCTBI and the current gMCTBI models. Both results agree with the experimental data. ${ }^{19}$ The negative charges on the DNA attract the cation $\mathrm{Na}^{+}$and exclude the anion $\mathrm{Br}^{-}$. According to the linear density profile predicted by the gMCTBI model (Figure 1B), the cation $\left(\mathrm{Na}^{+}\right)$accumulation can be classified into the strong accumulation region (several high peaks in the region $x<20 \AA$ ) and the weak accumulation region (a long tail at $x>20 \AA$ ). The DNA helix in a high- $\left[\mathrm{Na}^{+}\right]$ solution can attract more excess $\mathrm{Na}^{+}$ions (higher peaks) in the strong accumulation region, resulting in a stronger charge neutralization and consequently less excess $\mathrm{Na}^{+}$ions (a lower long tail) in the weak accumulation region. The decay of the linear density of the excess cations in the weak accumulation region can cause a lower total number $\Gamma_{\mathrm{Na}^{+}}$of the excess $\mathrm{Na}^{+}$ ions. In fact, the long tail of the excess $\mathrm{Na}^{+}$in the dilute $\left[\mathrm{Na}^{+}\right]$ can extend to more than $100 \AA$ into solution. As a result, $\Gamma_{\mathrm{Na}^{+}}$ decreases with the increase in $\left[\mathrm{Na}^{+}\right]$(see Figure 1A).

Similar to the cations, the depletion of $\mathrm{Br}^{-}$ions around the DNA can also be classified into the strong depletion (a deep valley) and weak depletion (a long tail) regions (Figure 1B). For a higher salt bulk concentration $[\mathrm{NaBr}]$, more anions $\mathrm{Br}^{-}$ would be excluded from the DNA helix due to the repulsion from the negatively charged backbone, leading to a valley in the linear density profile in the strong depletion region. In the meantime, the stronger charge neutralization (due to more excess $\mathrm{Na}^{+}$and depleted $\mathrm{Br}^{-}$in the strong accumulation/ depletion regions) results in weaker depletion effect for $\mathrm{Br}^{-}$in the weak depletion region (i.e., a higher long tail in the weak depletion region). In Figure 1B, we find that the difference in the long tails for $\mathrm{Br}^{-}$between high and low salt concentrations (e.g., between $\left[\mathrm{Na}^{+}\right]=200$ and $10 \mathrm{mM}$ ) is smaller than that for $\mathrm{Na}^{+}$. Therefore, different from $\Gamma_{\mathrm{Na}^{+}}$, whose trend with $\left[\mathrm{Na}^{+}\right]$is mainly governed by the long tail in the linear density profile, the overall depletion $\left(\Gamma_{\mathrm{Br}^{-}}\right)$of $\mathrm{Br}^{-}$is dominated by the number of the depleted $\mathrm{Br}^{-}$in the strong depletion region (deep valley), giving rise to the decrease of $\Gamma_{\mathrm{Br}^{-}}$with an increasing $\left[\mathrm{Na}^{+}\right]$.

As $\left[\mathrm{Na}^{+}\right]$changes, the net excess charge $\Gamma_{\text {tot }}=\sum_{\alpha} Z_{\alpha} \Gamma_{\alpha}=$ $\Gamma_{\mathrm{Na}^{+}}+\left|\Gamma_{\mathrm{Br}^{-}}\right|$( $\alpha=$ ion species $)$ remains near $+46 e$. Considering that the DNA backbone charge is equal to $-46 e$, the result here suggests that the DNA with the bound ions remains neutral. The MCTBI and the gMCTBI (with and without monovalent ion correlation, respectively) provide similar predictions for the excess and depletion number of ions. The result seems to suggest that the monovalent ion correlation effect might not be strong enough to cause significant differences in the total number of bound/repelled ions. However, previous studies based on the comparisons between MD simulation and NLPB model predictions indicated that the monovalent ion correlation effect could lead to different ion distributions near the surface of the nucleic acids ${ }^{61}$ (Section 2.4).

Because the gMCTBI model samples the discrete positions for each TB ion, particularly, the monovalent ion, which is treated with a continuum model in the original MCTBI model, gMCTBI can account for discrete distributions for both the monovalent and multivalent ions. As a result, one of the major improvements in the gMCTBI model is its ability to compute the fluctuations and ensemble (probability) distribution of the monovalent (as well the multivalent) ions [probability $p(k)$ of finding a $\mathrm{TB} \mathrm{Na}^{+}$ion at site $k$ ]. Describing ion binding at the level of discrete ion positions for monovalent ions can uncover 

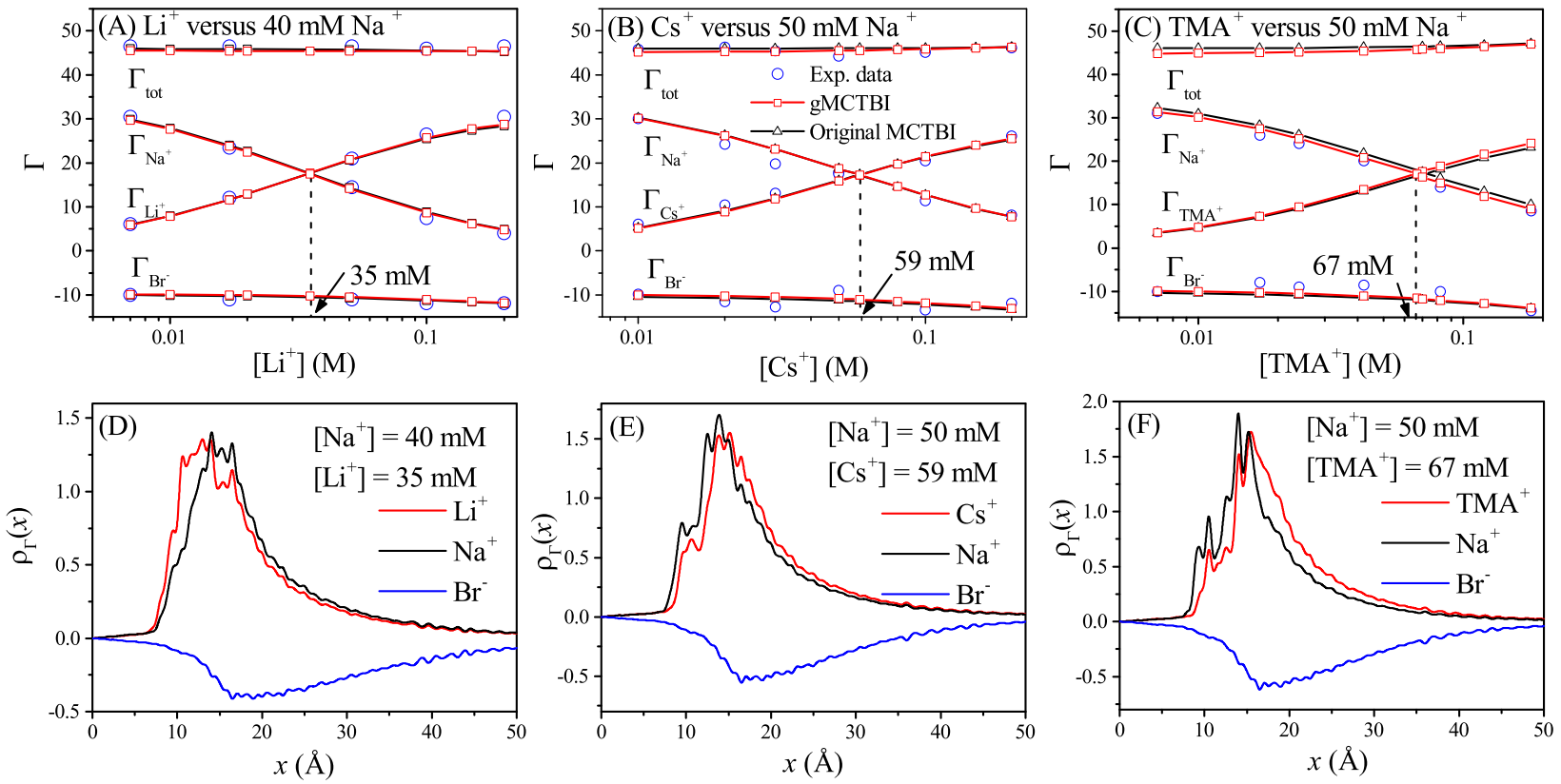

Figure 2. (A-C) Excess number of ions predicted by the gMCTBI (red lines with squares) and the original MCTBI (black lines with triangles) model for a mixed solution with (A) $\mathrm{Na}^{+}$and $\mathrm{Li}^{+}$, (B) $\mathrm{Na}^{+}$and $\mathrm{Cs}^{+}$, and (C) $\mathrm{Na}^{+}$and $\mathrm{TMA}^{+}$. The experiment data come from ref 55. (D-F) $\mathrm{Linear}$ density of the ions solved by the gMCTBI model corresponding to the cases in $(\mathrm{A})-(\mathrm{C})$, respectively.

many ion binding properties unattainable through the original MCTBI model.

The $\mathrm{Na}^{+}$ions in the strong accumulation region may dominate the nucleic acid-ion interactions because these ions show lower diffusion and closer interaction with the DNA. ${ }^{43}$ As shown in Figure 1B, there are three density peaks in the strong accumulation region. In fact, the three peaks in the linear density profile are mainly from the $\mathrm{TB} \mathrm{Na}^{+}$ions (see Figure S1 in SI). For peak 1 (Figure 1C), the closest peak to the DNA helix, the (fully hydrated) $\mathrm{Na}^{+}$ions are mainly distributed inside (and along) the deep, wide major groove of the DNA (see Figure 1C). For peak 2, in contrast, ions are mainly distributed around the minor groove. These hydrated ions are too bulky to enter the (narrow) minor groove. Physically, ions at peaks 1 and 2 are attracted to the major and minor groove regions due to the high DNA backbone charge densities in these regions. We note that the predicted ion probability distribution also shows scattered high-probability ion binding sites near the major groove. For regions (such as peak 3) further away from the DNA, the distinction between the groove and nongroove regions disappears and $\mathrm{TB} \mathrm{Na}^{+}$ions are more uniformly distributed around the DNA. Here, we should note that since the gMCTBI model does not account for the desolvation effect of the ions, the binding sites of dehydrated $\mathrm{Na}^{+}$ions and the corresponding density peak are not predicted.

Another important advantage of the gMCTBI model (vs the original MCTBI) is that it can give the most probable (discrete) distribution of the TB monovalent ions (see Figure 1D). At a low $\left[\mathrm{Na}^{+}\right]$(e.g., $10 \mathrm{mM}$ in Figure $\left.1 \mathrm{D}\right)$, the most probable distribution corresponds to $\mathrm{TB} \mathrm{Na}^{+}$ions distributed along the minor groove, presumably due to the high charge density in the (narrow) minor groove region. At a higher $\left[\mathrm{Na}^{+}\right]$, such as $100 \mathrm{mM}$, more $\mathrm{Na}^{+}$ions are populated and interact with the minor groove. Additionally, at high $\left[\mathrm{Na}^{+}\right]$ (200 $\mathrm{mM}$ in Figure 1D), in addition to the majority of ions, which are distributed in the minor groove region, there are $\mathrm{Na}^{+}$ ions (circles in the figure) distributed in the major groove region in the most probable distribution. Here, the most probable distribution of TB ions is determined by the manyion interaction energy of all of the bound ions (including TB and DB ions; see Section 4 in SI). Hence, a minor movement of the TB ions from the sites in the most probable distribution may not cause a dramatic increase in the interaction energy, suggesting that the TB ions may fluctuate around the bound sites of the most probable distribution.

2.2. Interplay between Different Monovalent Cations. The gMCTBI model allows us to further investigate the ion binding properties for a nucleic acid in a mixed salt solution, which contains background cations (bc) $\mathrm{Na}^{+}$and competing cations (cc) such as $\mathrm{Li}^{+}, \mathrm{Cs}^{+}$, or $\mathrm{TMA}^{+}$. Figure $2 \mathrm{~A}-$ $\mathrm{C}$ shows the excess bound ion number around a 24-bp DNA helix in various salt conditions. Experiment ${ }^{55}$-theory comparisons indicate that both the current gMCTBI model and the original MCTBI model can accurately predict the number of excess ions. The model predicts that as the bulk concentration of the competing cations [cc] is increased, more competing cations would bind to the DNA due to the lower entropic cost for ion binding. In the meantime, less background cations $\left(\mathrm{Na}^{+}\right)$are bound to the DNA. The slightly reduced depletion of $\mathrm{Br}^{-}\left(\Gamma_{\mathrm{Br}^{-}}\right)$is accompanied by a slight increase in the total number of excess cations $\left(\Gamma_{\mathrm{cc}}+\Gamma_{\mathrm{bc}}\right)$. The predicted results are similar to those for a single salt solution (see Figure 1A).

As shown in Figure $2 \mathrm{~A}-\mathrm{C}$, for the different salt solutions $\left[\mathrm{Li}^{+}\right]_{\mathrm{eq}} \approx 35 \mathrm{mM}$ (versus $40 \mathrm{mM} \mathrm{Na}$ ), $\left[\mathrm{Cs}^{+}\right]_{\mathrm{eq}} \approx 59 \mathrm{mM}$ (versus $50 \mathrm{mM} \mathrm{Na}^{+}$), and $\left[\mathrm{TMA}^{+}\right]_{\mathrm{eq}} \approx 67 \mathrm{mM}$ (versus $50 \mathrm{mM}$ $\mathrm{Na}^{+}$), respectively, the competing and the background cations show a similar number of excess ions for the three solutions. Here, $[\mathrm{cc}]_{\mathrm{eq}}$ denotes the competing cation concentration under which the competing cation and background cation reach an equal number of excess ions: $\Gamma_{c c}=\Gamma_{b c}$. Although the different solutions show a similar number of excess ions, smaller cations are more competitive and show higher peaks in the close vicinity of the DNA (and lower peaks and tails in regions away 

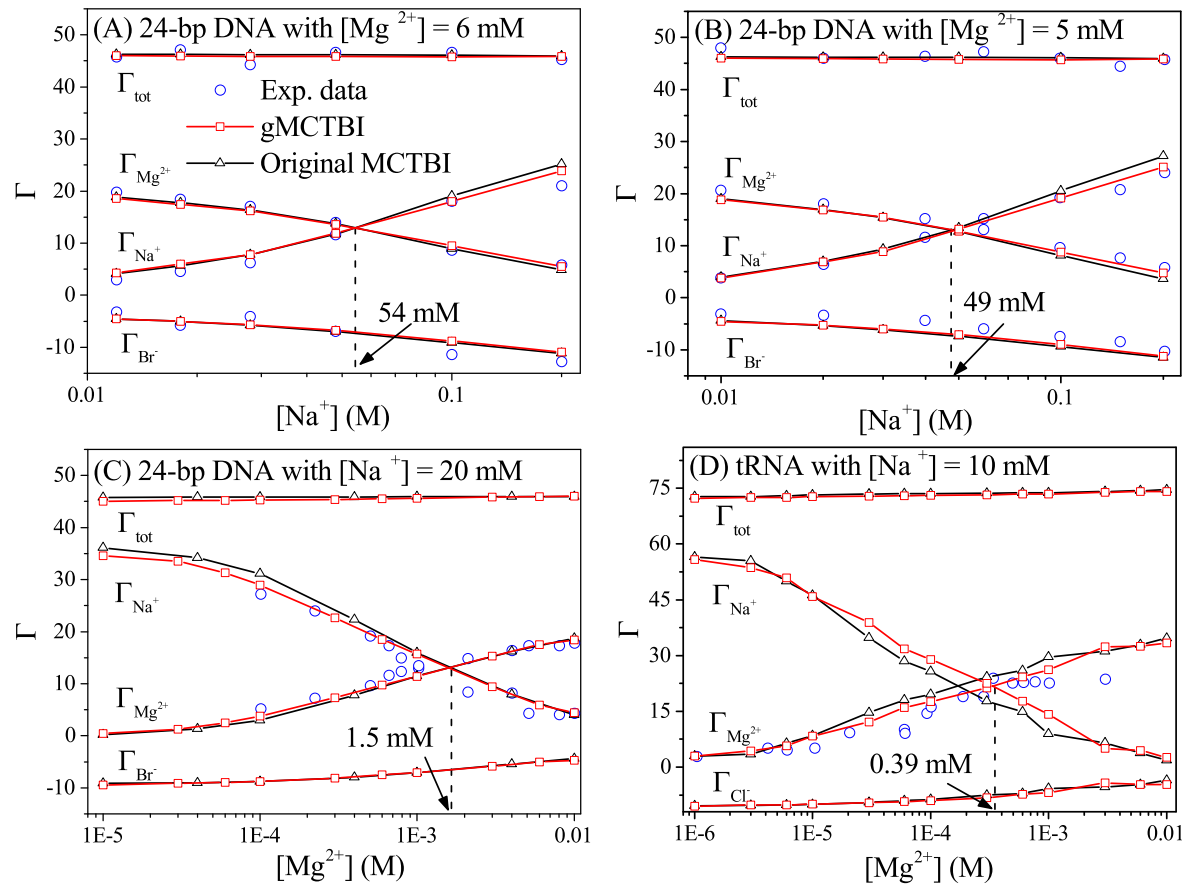

Figure 3. Ion excess number predicted by the gMCTBI (red lines with squares) and the original (black lines with triangles) MCTBI models for (A) $6 \mathrm{mM}$ background $\mathrm{Mg}^{2+}$ ion mixed with $\mathrm{Na}^{+}$, (B) $5 \mathrm{mM}$ background $\mathrm{Mg}^{2+}$ mixed with $\mathrm{Na}^{+}$, (C) $20 \mathrm{mM}$ background $\mathrm{Na}^{+}$mixed with $\mathrm{Mg}^{2+}$ for a $24-$ bp DNA, and (D) $10 \mathrm{mM}$ background $\mathrm{Na}^{+}$mixed with $\mathrm{Mg}^{2+}$ for a 76-nt tRNA (PDB id: 1TRA ${ }^{81}$ ). Here, the experimental data are adopted from ref 55 for (A), ref 17 for (B) and (C), and ref 78 for (D).

from the DNA; see Figure 2D-F). The result indicates that the smaller cations are bound to the DNA more tightly. The predictions agree with previous results based on 3 D-RISM ${ }^{62}$ and MD simulations. ${ }^{58}$

2.3. Interplay between Monovalent and Divalent Ions. As shown in Figure $3 \mathrm{~A}-\mathrm{C}$ for the 24-bp DNA duplex and Figure 3D for a tRNA in various salt conditions, gMCTBI gives overall improved predictions than the original MCTBI. Furthermore, the results reveal an intriguing interplay between the monovalent cation, the divalent cation, and the anion. For a solution containing background cations and competing cations, an increase in the competing cation concentration would lead to more competing cations and less background cations bound to the nucleic acid.

For a mixed monovalent-divalent salt solution, as shown in Figure 3A,B (with $\mathrm{Mg}^{2+}$ as the background cation), for a 24-bp DNA helix, the number of excess background cation $\mathrm{Mg}^{2+}$ and competing cation $\mathrm{Na}^{+}$reaches equilibrium at 54 and $49 \mathrm{mM}$ $\mathrm{Na}^{+}$in the background of 6 and $5 \mathrm{mM} \mathrm{Mg}^{2+}$, respectively. The total excess charge $\Gamma_{\text {tot }}$ keeps the nucleic acid neutralized. For solutions with $\mathrm{Na}^{+}$as the background cation, as shown in Figure 3C (for the 24-bp DNA) and Figure 3D (for a tRNA), the equilibrium occurs at 1.5 and $0.39 \mathrm{mM} \mathrm{Mg}^{+}$(competing cation) with background cation concentrations of 20 and 10 $\mathrm{mM} \mathrm{Na}{ }^{+}$, respectively. The results show quantitatively the monovalent-divalent ion competition.

For a solution with $\mathrm{Mg}^{2+}$ as the background cation (Figure $3 \mathrm{~A}, \mathrm{~B})$, the depletion number of the anions decreases with the increase in $\left[\mathrm{Na}^{+}\right]$of the competing cation, whereas in the cases with $\mathrm{Na}^{+}$as the background (Figure 3C,D), the depletion number of the anions increases with $\left[\mathrm{Mg}^{2+}\right]$. The above trend of $\Gamma_{\mathrm{Cl}^{-}}\left(\mathrm{or} \mathrm{Br}^{-}\right)$is a result of the decrease/increase in the number of bound $\mathrm{Mg}^{2+}$ ions, which dominate over $\mathrm{Na}^{+}$ions in RNA binding. As more $\mathrm{Mg}^{2+}$ ions are bound to the nucleic acid, less anions will be excluded in the region far away from the nucleic acid, resulting in an increase in $\Gamma_{\mathrm{Cl}^{-}}$(or $\left.\mathrm{Br}^{-}\right)$.

Moreover, even in the solution mixed with $\mathrm{Mg}^{2+}$ ions, the entire nucleic acid-solution system still keeps charge neutrality (see Figure 3). In fact, in a small space around a phosphate, we might observe the charge inversion (the change of net charge sign) or even a giant charge inversion ${ }^{75}$ (net charge large than $+e$ ) if one or two $\mathrm{TB} \mathrm{Mg}^{2+}$ ions are bound to a phosphate. However, in other regions beyond the small space above, phosphates in the nucleic acid and the TB cation-attracted anions can neutralize the inverse net charge in the local space around a phosphate. We also note that the charge inversion phenomenon of the entire nucleic acid-solution system can indeed be observed for trivalent or higher-valency cations. ${ }^{74,76}$

2.4. Effect of the Monovalent Ion Correlation. For a solution of (single or mixed) monovalent cations, neglecting the monovalent ion correlation effect may still provide good estimations for the ion excess number (see Figures $1 \mathrm{~A}$ and $2 \mathrm{~A}-\mathrm{C})$. However, the explicit sampling of discrete monovalent ion distributions in the gMCTBI model, which accounts for ion correlation effects, can provide more detailed information such as ion spatial distributions (see Figure 1C,D). In fact, other ion binding properties beyond the excess number of ions suggest that the ion correlation effect is indeed important for the monovalent ions around the nucleic acid even if the solution contains only monovalent ions. For example, the linear density profiles in Figure 4A shows that monovalent ion-monovalent ion correlation can promote $\mathrm{Na}^{+}$accumulation near the DNA surface. This is because ion correlation lowers the Coulomb energy through the cooperative organization of the ions and thus induces more ions to bind to the nucleic acid. The finding agrees with the predictions from 3D-RISM and MD simulations, ${ }^{61}$ which also suggested 


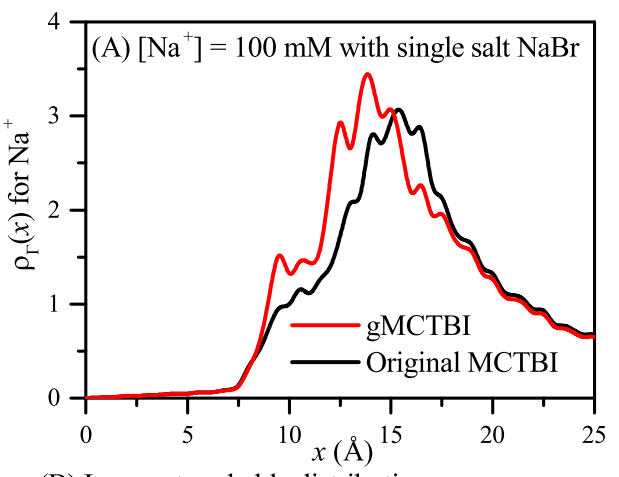

(B) Ion most probable distributions

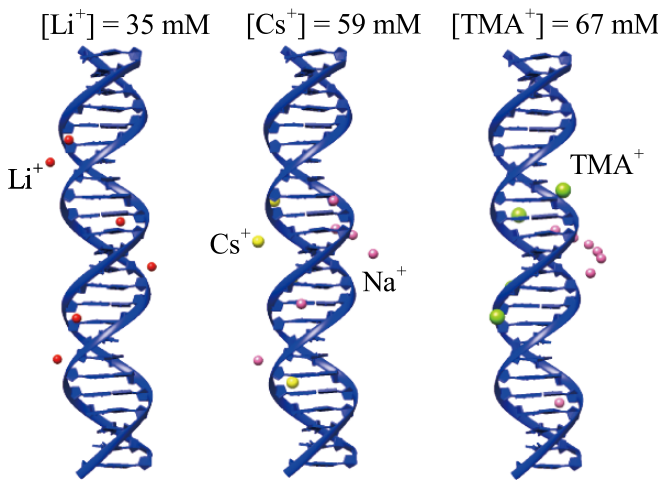

Figure 4. (A) Comparison of linear density for $\mathrm{Na}^{+}$around the 24-bp DNA helix between the predictions from the original MCTBI (black) and the gMCTBI model. (B) Most probable distributions of the background ions and the competing ions: $40 \mathrm{mM} \mathrm{Na}^{+}$versus $35 \mathrm{mM}$ $\mathrm{Li}^{+}, 50 \mathrm{mM} \mathrm{Na}^{+}$versus $59 \mathrm{mM} \mathrm{Cs}^{+}$, and $50 \mathrm{mM} \mathrm{Na}^{+}$versus $67 \mathrm{mM}$ $\mathrm{TMA}^{+}$. Red, yellow, purple, and green balls represent the $\mathrm{Li}^{+}, \mathrm{Cs}^{+}$, $\mathrm{Na}^{+}$, and $\mathrm{TMA}^{+}$ions, respectively.

that there are more cations near the DNA surface than that predicted by mean-field theory.

The correlation effect for monovalent ions can enhance the ion-ion competition near the DNA surface. Figure 4B shows the most probable distributions of the TB ions in the presence of competing cations at concentration $[\mathrm{cc}]_{\mathrm{eq}}$. In the case of $\mathrm{Li}^{+}-\mathrm{Na}^{+}$competition, $\mathrm{Li}^{+}$ions are found to be distributed only along the minor groove of the DNA helix. However, for the bulkier competing cations $\left(\mathrm{Cs}^{+}\right.$and $\left.\mathrm{TMA}^{+}\right)$, more $\mathrm{Na}^{+}$ions are found to bind to the DNA ( $\operatorname{six~} \mathrm{Na}^{+}$ions versus three $\mathrm{Cs}^{+}$ions and seven $\mathrm{Na}^{+}$ions versus three $\mathrm{TMA}^{+}$ions, respectively). Therefore, even though the DNA attracts the same total (excess) number of cations, the smaller cations win the competition (against the larger cation) and are more likely to be found in the close vicinity of the DNA surface. However, as a caveat, we note that ion dehydration is not considered here. A smaller ion may bind more tightly with the DNA, but, on the other hand, it is less likely to dehydrate as water molecules wrap around smaller ions more tightly. ${ }^{58}$ In the future, we need to develop a model that can integrate hydration with the correlation effect for bound monovalent cations.

For a $\mathrm{Na}^{+}-\mathrm{Mg}^{2+}$ mixed solution, compared with the original MCTBI model, as shown in Figure 3, the gMCTBI model can give overall improved predictions for the ion excess number in the ion atmosphere. The result suggests the importance to consider the $\mathrm{Na}^{+}-\mathrm{Mg}^{2+}$ ion correlation. In fact, previous studies have suggested the importance of such a correlation effect in other macromolecular systems such as protein solutions. $^{77}$ For the 24-bp DNA helix system, the original
MCTBI model, which ignores the $\mathrm{Na}^{+}-\mathrm{Mg}^{2+}$ ion correlation, overestimates the excess bound $\mathrm{Na}^{+}$ions. The correlation effect is more pronounced for systems involving a larger number of monovalent bound cations, such as solutions with high $\left[\mathrm{Na}^{+}\right]$in a fixed $\mathrm{Mg}^{2+}$ background (Figure 3A,B) or with low $\left[\mathrm{Mg}^{2+}\right]$ in a fixed $\mathrm{Na}^{+}$background (Figure $3 \mathrm{C}$ ). For the tRNA, Figure 3D shows that the original MCTBI model underestimates the excess number of $\mathrm{Na}^{+}$ions due to neglecting the $\mathrm{Na}^{+}-\mathrm{Na}^{+}$correlation effect.

As shown by the linear density in Figure 5 for the 24-bp DNA helix at high $(200 \mathrm{mM}) \mathrm{Na}^{+}$with $5 \mathrm{mM}$ background

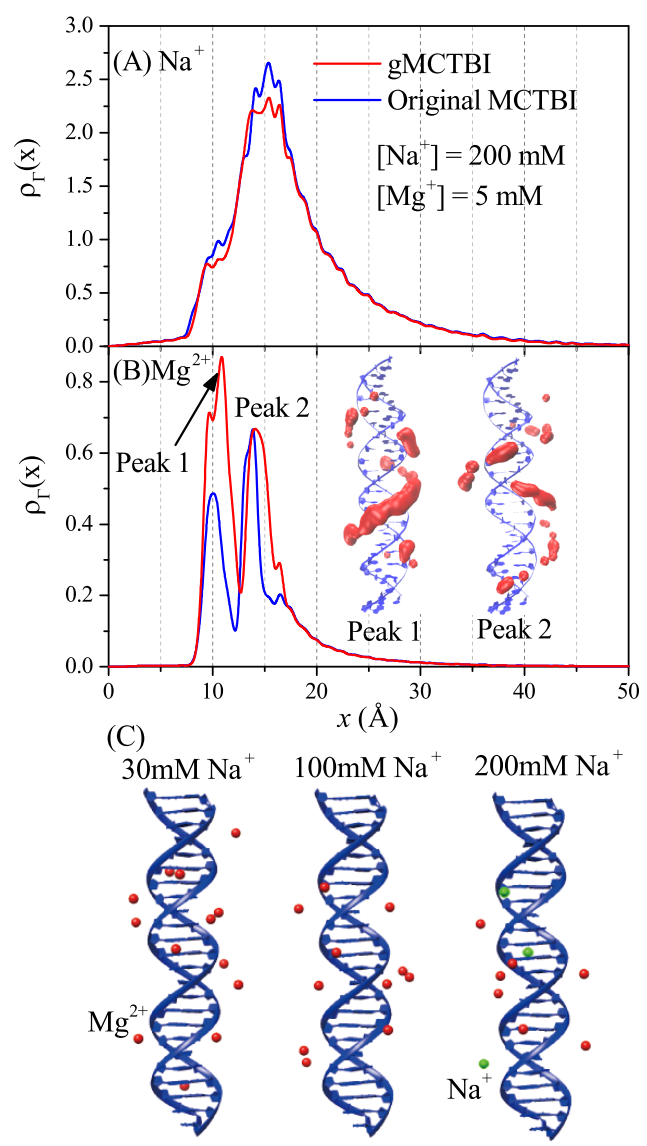

Figure 5. (A, B) Linear density of the bound (A) $\mathrm{Na}^{+}$and (B) $\mathrm{Mg}^{2+}$ ions around a 24-bp DNA helix in the solution with $200 \mathrm{mM} \mathrm{Na}^{+}$and $5 \mathrm{mM} \mathrm{Mg}{ }^{2+}$. The inset in (B) shows the accumulated $\mathrm{Mg}^{2+}$ ions around the DNA helix corresponding to the two peaks. (C) Most probable distributions of the TB ions in the solution containing $5 \mathrm{mM}$ background $\mathrm{Mg}^{2+}$ ions mixed with $\left[\mathrm{Na}^{+}\right]=30,100$, and $200 \mathrm{mM} \mathrm{Na}$. The red and green balls denote the $\mathrm{Mg}^{2+}$ and $\mathrm{Na}^{+}$ions, respectively

$\mathrm{Mg}^{2+}$, the original MCTBI overestimates $\mathrm{Na}^{+}$binding and underestimates $\mathrm{Mg}^{+}$binding near $x=10$ and $15 \AA$. The result is due to the missing correlation effect for $\mathrm{Na}^{+}$ions in the original MCTBI model. For $\mathrm{Na}^{+}$ion binding, although as shown in Figure $4 \mathrm{~A}$, the $\mathrm{Na}^{+}-\mathrm{Na}^{+}$correlation can enhance $\mathrm{Na}^{+}$binding (through multi-ion cooperative organization), the $\mathrm{Na}^{+}-\mathrm{Mg}^{2+}$ correlation (mainly repulsive through discrete charge-charge volume exclusion and Coulombic repulsion) causes a reduction in $\mathrm{Na}^{+}$binding (see Figure 5A). Therefore, the original MCTBI model, which ignores the effect of discrete $\mathrm{Na}^{+}$ions and the $\mathrm{Na}^{+}-\mathrm{Mg}^{2+}$ correlation in the $\mathrm{TB}$ region, overestimates $\mathrm{Na}^{+}$ion binding. Furthermore, as shown in Figure $5 \mathrm{~B}$, the reduced $\mathrm{Na}^{+}$ion binding results in an increased 
$\mathrm{Mg}^{2+}$ binding. However, in a solution of high $\left[\mathrm{Mg}^{2+}\right]$ with background $\mathrm{Na}^{+}$or a dilute $\left[\mathrm{Na}^{+}\right]$solution with background $\mathrm{Mg}^{2+}$, ion binding is dominated by $\mathrm{Mg}^{2+}$ and the $\mathrm{Na}^{+}$-involved correlation effect is weaker than the $\mathrm{Mg}^{2+}-\mathrm{Mg}^{2+}$ correlation. Therefore, the gMCTBI model and the original MCTBI model, which differ only in the treatment of the monovalent ion-induced correlation effect, give similar predictions for the excess number of bound ions.

The density plot for $\mathrm{Mg}^{2+}$ (Figure 5B) shows two peaks. Our predictions for the most probable ion distributions (Figure 5C) indicate that the two peaks correspond to bound cations in the major and minor grooves, respectively. For low $\left[\mathrm{Na}^{+}\right]$ $(30 \mathrm{mM})$, the gMCTBI model predicts that only $\mathrm{Mg}^{2+}$ ions are closely distributed around the DNA. As $\left[\mathrm{Na}^{+}\right]$increases, less $\mathrm{Mg}^{2+}$ ions are found near the DNA surface. Only at high $\left[\mathrm{Na}^{+}\right]$, such as $200 \mathrm{mM}\left(>\left[\mathrm{Na}^{+}\right]_{\mathrm{eq}}\right), \mathrm{Na}^{+}$ions are found in the close vicinity of the DNA surface in the most probable ion distribution.

For the tRNA case, as shown in Figure 3D, for a limited range in $\left[\mathrm{Mg}^{2+}\right]<1 \mathrm{mM}$, the gMCTBI model predicts a higher $\Gamma_{\mathrm{Na}^{+}}$and a lower $\Gamma_{\mathrm{Mg}^{2+}}$ than that predicted by the original MCTBI model. The predictions by the gMCTBI model are in better agreement with the experimental data. ${ }^{78}$ Unlike the DNA helix, the tRNA has a more complicated compact structure, so we use the distance $x$ to the RNA surface as the $\mathrm{x}$ axis to draw the linear density. According to the linear density for $\mathrm{Na}^{+}$shown in Figure $6 \mathrm{~A}$, at $\left[\mathrm{Mg}^{2+}\right]=0.6 \mathrm{mM}$, the gMCTBI-predicted $\mathrm{Na}^{+}$linear density is higher than the original MCTBI-predicted result. The reason is that the gMCTBI model can treat the discrete $\mathrm{Na}^{+}$ions, whereas the previous MCTBI model cannot. For the complicated 3D structure of the tRNA, $\mathrm{Na}^{+}$ions (green balls in Figure 6B) can be trapped in the pockets that cannot be occupied by the

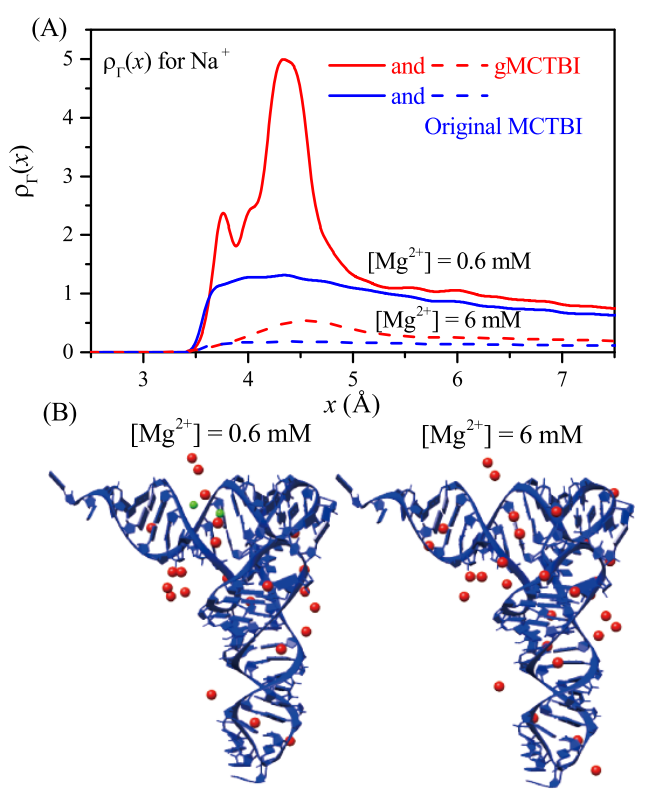

Figure 6. (A) Linear density of $\mathrm{Na}^{+}$ions around the tRNA predicted by the gMCTBI (red lines) and the original (blue line) MCTBI models for solutions containing $10 \mathrm{mM}$ background $\mathrm{Na}^{+}$mixed with $0.6 \mathrm{mM}$ competing $\mathrm{Mg}^{2+}$ (solid lines) and $6 \mathrm{mM}$ competing $\mathrm{Mg}^{2+}$ (dash lines), respectively. (B) Most probable distributions of the TB ions in a solution containing $10 \mathrm{mM}$ background $\mathrm{Na}^{+}$mixed with $\mathrm{Mg}^{2+}$. The red and green balls denote the $\mathrm{Mg}^{2+}$ and $\mathrm{Na}^{+}$ions, respectively bulkier $\mathrm{Mg}^{2+}$. The trapped $\mathrm{Na}^{+}$ions would cause an effective (excluded volume and electrostatic) repulsive force on the TB $\mathrm{Mg}^{2+}$ ions near the pockets. Such scenarios, which can be well predicted by the current gMCTBI model, cannot be treated by the original MCTBI model. In a solution with higher $\left[\mathrm{Mg}^{2+}\right]$, more $\mathrm{TB} \mathrm{Mg}^{2+}$ ions would be found in the $\mathrm{TB}$ region. The stronger $\mathrm{Mg}^{2+}-\mathrm{Na}^{+}$(repulsive) correlation effect tends to exclude/displace the trapped $\mathrm{Na}^{+}$ions (see the case of $\left[\mathrm{Mg}^{2+}\right]$ $=6 \mathrm{mM}$ in Figure $6 \mathrm{~B}$ ). As a result, the difference between the gMCTBI and MCTBI predictions becomes smaller.

\section{CONCLUSIONS}

To summarize, we have developed a new model, the gMCTBI model, to predict the ion binding properties for nucleic acids. The model can treat discrete ion positions and correlations and ion fluctuations for both multivalent and monovalent ions. Theory-experiment tests for ion binding properties in monovalent and monovalent-divalent solutions support the validity of the gMCTBI predictions. In a solution with (single or mixed) monovalent ions, although the gMCTBI and the mean-field methods predict similar global binding properties (such as the excess number of monovalent ions), the gMCTBI model, which can treat discrete, correlated monovalent ion distributions, may provide more reliable predictions for the linear density for the bound ions and the most probable ion distributions. Furthermore, the gMCTBI model distinguishes from the original MCTBI model in the treatment of monovalent ions. Therefore, the differences between the predictions from the two models reveal significant effects of the monovalent ion-involved correlations.

For a mixed solution of different species of monovalent ions, the gMCTBI model, which accounts for discrete monovalent ions, can account for the ion size effect in ion binding accessibility. Smaller ions can enter narrow grooves that are not accessible to bulkier ions and hence are more competitive in ion binding. For a mixed monovalent-divalent ion solution, the gMCTBI model shows that divalent ions can be more than 9-fold more competitive than monovalent ions. For example, for a 24-bp DNA helix, the model predicts the ion concentrations for reaching equal number of the excess ions: $54 \mathrm{mM} \mathrm{Na}^{+}$versus $6 \mathrm{mM} \mathrm{Mg}{ }^{2+}, 49 \mathrm{mM} \mathrm{Na}^{+}$versus $5 \mathrm{mM}$ $\mathrm{Mg}^{2+}$, and $20 \mathrm{mM} \mathrm{Na}^{+}$versus $1.5 \mathrm{mM} \mathrm{Mg}^{2+}$.

The interplay between the different species of ions depends on the $3 \mathrm{D}$ structure of the nucleic acid. For example, a less bulky (hydrated) monovalent ion can more likely bind to RNA narrow pockets, which may be inaccessible to bulkier divalent ions. Such phenomena become more significant for more complicated nucleic acid structures such as tRNA, which can contain various narrow pocket sites for ion binding. Only at high divalent ion concentrations can the monovalent ions be displaced from the binding pockets (due to the repulsion from the divalent ions).

The framework of the gMCTBI model may be applicable to other systems such as highly charged surfaces and charged proteins. However, as a caveat, we note that the current form of the model ignores anion-involved correlations. Recent experiments ${ }^{19,55}$ reported that a monovalent cation and a monovalent anion could form an ionic cluster near the DNA surface, indicating that the ion-involved correlation may be important in ion-nucleic acid interactions. Therefore, future development of the model would include anion correlation effects by explicitly sampling the distribution of discrete anions. 


\section{MATERIALS AND METHODS}

4.1. Preparations for the Theoretical Predictions. We use the modeling of ion effects for two nucleic acid structures to illustrate the gMCTBI: a 24-base pair (24-bp) B-form DNA and a 76-nt yeast tRNA ${ }^{\text {Phe }}$. The $3 \mathrm{D}$ structure of the 24-bp DNA is generated from the latest version (version 2.1) of the program X3DNA, ${ }^{79}$ whereas the structure of tRNA $^{\text {Phe }}$ is downloaded from the protein data bank $(\mathrm{PDB})^{80}$ and its PDB ID is 1TRA. ${ }^{81}$ In this study, we use the same sequences as the ones used in the experimental study for the B-DNA helix: ${ }^{55} \mathrm{~S} 1$ $=5^{\prime}$-GGT GAC GAG TGA GCT ACT GGG CGG-3' and S2 $=5^{\prime}$-CCG CCC AGT AGC TCA CTC GTC ACC-3'. A coarse-grained $(C G)$ charge model is used ${ }^{72,73}$ where each phosphorus atom carries an electronic charge $(-e)$ and other atoms are treated as neutral. The CG charge model, however, cannot account for the sequence-dependence of the charge distribution on the nucleic acids. Therefore, the predictions from the gMCTBI model are dependent on the nucleic acid structure but not the sequence. Here, we should note that because the 24-bp DNA carries -46e net charges, ${ }^{17,19,55}$ we manually deleted the $5^{\prime}$ terminal phosphates in both chains of the 24-bp DNA helix.

To reduce the boundary effect, the nucleic acid is placed in a large solution box, whose size is larger than 6 times Debye length. To test the model, various salt conditions are used, including single salt and mixed salt (with two cation species) conditions. All solutions contain $\mathrm{Na}^{+}$either as the single species cation or as the background in a mixed salt solution. For the mixed salt, the other cation species may be monovalent ions, $\mathrm{Li}^{+}, \mathrm{Cs}^{+}$, and tetramethylammonium ion $\left(\mathrm{TMA}^{+}\right)$, or divalent ions $\mathrm{Mg}^{2+}$. The bulk concentrations in the solution satisfy the charge neutrality condition: $\sum\left(Z_{i} c_{i}\right)^{+}=c^{-}$, where $Z_{i}$ and $c_{i}$ denote the charge and the bulk concentration of the cation species $i$, respectively, and $c^{-}$is the bulk concentration of an anion $\left(\mathrm{Br}^{-}\right.$or $\left.\mathrm{Cl}^{-}\right)$. Ions are considered to be fully hydrated in our calculations. For $\mathrm{Na}^{+}, \mathrm{Mg}^{2+}$, and $\mathrm{Cl}^{-}$, their (hydrated) ion radii are $3.5,4.5$, and $4.0 \AA$, respectively. We note that these are the same parameters used in the previous studies. ${ }^{65,72,73}$ The $\mathrm{Mg}^{2+}$ and the $\mathrm{Na}^{+}$ion radii correspond to two and one hydrated shells, respectively. ${ }^{82,83}$ Previous experiments ${ }^{19,55}$ suggested that as the anion $\mathrm{Cl}^{-}$is replaced with $\mathrm{Br}^{-}$, the ion binding effects remain nearly the same. Thus, we set the effective $\mathrm{Br}^{-}$radius the same $(4.0 \AA)$ as that of $\mathrm{Cl}^{-}$. For other alkali cations $\mathrm{Li}^{+}(3.1 \AA)$ and $\mathrm{Cs}^{+}(4.1 \AA)$, their radii are estimated from the difference in van der Waals radius ${ }^{84}$ between the cation $\left(\mathrm{Li}^{+}\right.$or $\left.\mathrm{Cs}^{+}\right)$and $\mathrm{Na}^{+}$and the hydrated $\mathrm{Na}^{+}$ radius. ${ }^{85,86}$ Additionally, the radius of the (hydrated) organic cation $\mathrm{TMA}^{+}$is assumed to be $4.65 \AA{ }^{87}$

4.2. Modeling the Monovalent Ion Correlation Effect. The gMCTBI model is developed based on the original MCTBI model $^{72}$ (see SI for a brief summary of the MCTBI model). The major difference between the gMCTBI model developed here and the original MCTBI model is the different treatments of the monovalent cations.

4.2.1. TB Regions for the Different Types of Cations. The NLPB calculation is employed to roughly estimate the ion concentration around a given nucleic acid. Based on the ion concentration, the ion correlation strength at a given position $x$ can be calculated as

$$
\begin{aligned}
& C(x)=\frac{z_{i} z_{j} e^{2}}{k_{\mathrm{B}} T \varepsilon_{\mathrm{w}}^{2} \sqrt{a_{\mathrm{ws}}^{i}(x) a_{\mathrm{ws}}^{j}(x)}} \\
& \frac{4 \pi}{3}\left[a_{\mathrm{ws}}^{i(\text { or } j)}(x)\right]^{3}\left[c_{i(\text { or } j)}(x)-c_{i(\text { or } j)}^{0}\right]=1
\end{aligned}
$$

here, superscripts (or subscripts) $i$ and $j$ denote the ion species. In the above equation, $i$ and $j$ can be the same or different ion species. $z, k_{\mathrm{B}}, T\left(=25^{\circ} \mathrm{C}\right.$ in our calculations $)$, and $\varepsilon_{\mathrm{w}}(\approx 78$ at room temperature) are the charge (valency), Boltzmann constant, temperature, and solvent dielectric constant, respectively. $a_{\mathrm{ws}}(x)$ and $c(x)$ denote the Wigner-Seitz radius ${ }^{88}$ and the local ion concentration at position $x$, respectively. $c^{0}$ is the bulk concentration in the solution. The region with ion correlation strength $C(x)$ larger than 2.6 (the critical value for the gaseous to liquid phase transition for an ion system ${ }^{42}$ ) is defined as the $\mathrm{TB}$ region.

One of the important features that distinguish the gMCTBI model from the original MCTBI model is the different TB regions. Here, we use a 24-bp B-DNA in a mixed solution of $\left[\mathrm{Mg}^{2+}\right]=10 \mathrm{mM}$ and $\left[\mathrm{Na}^{+}\right]=100 \mathrm{mM}$ as an example. In the original MCTBI model, monovalent ions are completely excluded from the consideration of ion correlation, and as shown in Figure 7A, the TB region is defined only for $\mathrm{Mg}^{2+}$

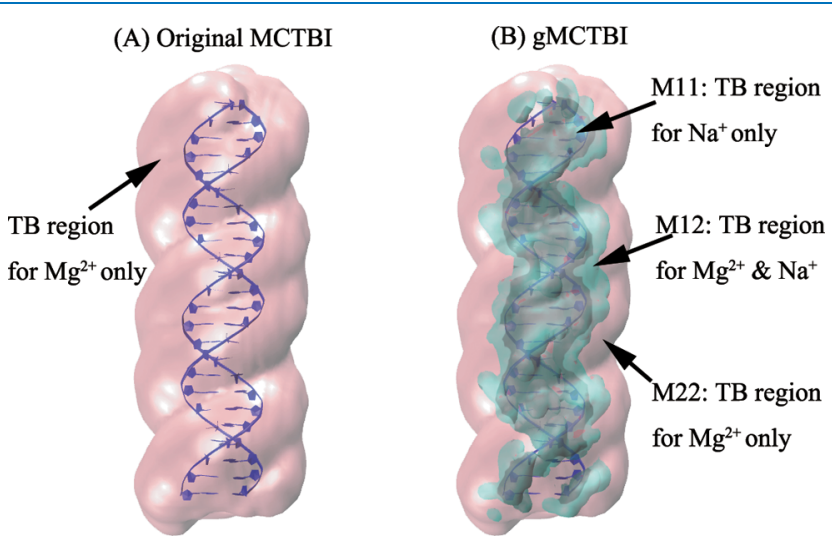

Figure 7. TB regions in the (A) original MCTBI model and (B) gMCTBI model. The 24-bp DNA structure is labeled by blue color. The black, cyan, and pink regions correspond to the TB regions for $\mathrm{Na}^{+}-\mathrm{Na}^{+}, \mathrm{Na}^{+}-\mathrm{Mg}^{2+}$, and $\mathrm{Mg}^{2+}-\mathrm{Mg}^{2+}$ correlations, respectively.

ions. In contrast, in the gMCTBI model, as shown in Figure $7 \mathrm{~B}$, we distinguish three parts of the $\mathrm{TB}$ region according to the different ion species (i.e., different $i$ and $j$ 's in eq 1). For a mixed divalent/monovalent $\left(\right.$ such as $\left.\mathrm{Mg}^{2+} / \mathrm{Na}^{+}\right)$salt solution, the M22 region is the part for $\mathrm{Mg}^{2+}$ only $\left(i=j=\mathrm{Mg}^{2+}\right.$ in eq 1$)$, the M12 region is the part for both $\mathrm{Mg}^{2+}$ and $\mathrm{Na}^{+}$ simultaneously $\left(i=\mathrm{Mg}^{2+}\right.$ and $j=\mathrm{Na}^{+}$in eq 1$)$, and the M11 region is the part for $\mathrm{Na}^{+}$only $\left(i=j=\mathrm{Na}^{+}\right.$in eq 1$)$.

The three parts of the TB region are determined separately by eq 1 . Basically, the M22 region is usually the largest because the $\mathrm{Mg}^{2+}-\mathrm{Mg}^{2+}$ correlation is the strongest. The M12 region is accessible to both TB $\mathrm{Na}^{+}$and $\mathrm{Mg}^{2+}$ ions. Because of the weaker $\mathrm{Na}^{+}-\mathrm{Mg}^{2+}$ (than $\mathrm{Mg}^{2+}-\mathrm{Mg}^{2+}$ ) correlation, the M12 region is thinner than the M22 region. The M11 region, which may be accessible to $\mathrm{Na}^{+}$but not to $\mathrm{Mg}^{2+}$ due to the bulky size of a fully hydrated $\mathrm{Mg}^{2+}$, is the closest to the surface of the nucleic acid and the thinnest $\left(<0.5 \AA\right.$ in thickness $\left.{ }^{42}\right)$. In fact, in a dilute monovalent cation solution, the M11 and M12 regions could disappear. To make sure that there is enough space for 
explicit sampling of the discrete distributions of monovalent cations, we set layers with $0.5 \AA$ minimum thickness for the M11 and M12 regions, respectively. In addition to the radii of atoms and the hydrated ions, the $\mathrm{TB} \mathrm{Na}^{+}$can be found at a distance $\sim 15 \AA$ from the helix axis. In particular, for the M11 region, if only based on the ion correlation strength calculated from eq 1 , the thickness of the region is much less than $0.5 \AA$ even at high $\left[\mathrm{Na}^{+}\right]$. Therefore, in the solution with pure monovalent ions, almost all of the TB ions are located in the M11 region. However, for these TB ions, the correlation exists although it may be weak. The M11 region is set up such that, compared with the implicit method, the explicit treatment for ions can provide a higher-resolution description for the bound ions near the nucleic acid surface.

4.2.2. Partition Function. To take into account the monovalent ion effects, in the gMCTBI model, we compute the partition function $(\mathrm{PF})$ of a nucleic acid-solution in a way such that the different species of ions (monovalent and multivalent ions) are treated equally. Specifically, for a given nucleic acid with $N_{\mathrm{p}}$ nucleotides, the PF is calculated from

$$
Z=\sum_{N_{\mathrm{b}}^{i}=0}^{N_{\max }^{i}} \sum_{N_{\mathrm{b}}^{j}=0}^{N_{\max }^{j}} Z\left(N_{\mathrm{b}}^{i}, N_{\mathrm{b}}^{j}\right)
$$

here, superscripts (or subscripts) $i$ and $j$ represent the ion species. $N_{\mathrm{b}}$ and $N_{\max }$ denote the number and the maximum saturated number of $\mathrm{TB}$ ions in the $\mathrm{TB}$ region, respectively. Similar to the original MCTBI model, ${ }^{72}$ we assume that the maximum allowed TB ion numbers correspond to the reversal of the net nucleic acid charge

$$
z_{i} \times N_{\max }^{i}+z_{j} \times N_{\max }^{j}=2 N_{\mathrm{p}}
$$

Here, we note that $N_{\max }^{i}$ and $N_{\max }^{j}$ are determined by the MCID process described in the following text.

$Z\left(N_{\mathrm{b}}^{i}, N_{\mathrm{b}}^{i}\right)$ in eq 2 is the partition function over all of the ion distributions with $N_{\mathrm{b}}^{i}$ TB ion $i$ and $N_{\mathrm{b}}^{j}$ TB ion $j$ in the TB region. $Z\left(N_{\mathrm{b}}^{i}, N_{\mathrm{b}}^{j}\right)$ is computed as

$$
\begin{aligned}
Z\left(N_{\mathrm{b}}^{i}, N_{\mathrm{b}}^{j}\right)= & Z_{\mathrm{id}}\left[\left(c_{i}^{0}\right)^{N_{\mathrm{b}}^{i}} \prod_{n_{i}=1}^{N_{\mathrm{b}}^{i}} \frac{w\left(n_{i}\right)}{n_{i}}\right]\left[\left(c_{j}^{0}\right)^{N_{\mathrm{b}}^{j}} \prod_{n_{j}=1}^{N_{\mathrm{b}}^{j}} \frac{w\left(n_{\mathrm{j}}\right)}{n_{j}}\right] \\
\mathrm{e}^{-\Delta G_{\mathrm{d}} / k_{\mathrm{B}} T} &
\end{aligned}
$$

here, $Z_{\text {id }}$ is the PF for the (ideal) solution without the nucleic acid and $c^{0}$ denotes the bulk concentration of the ion. The product "П" corresponds to the insertion process of the TB ions. $w(n)$ is the statistical weight arising from the $n$th step of the insertion and is dependent on the pre-existing ion distribution in the TB region (see eq $\mathrm{S} 1$ in SI). $\Delta G_{\mathrm{d}}$ is the electrostatic free energy for the DB ions (see eq S3 in SI). One of the key ingredients in the model is the sampling of the TB ion distributions using the MCID algorithm, in particular, for the monovalent ions; see below.

4.2.3. Monte Carlo Insertion Deletion (MCID) Algorithm. We consider a divalent/monovalent ion mixed solution. To sample the TB ions, we first insert the ions one by one into the TB region. For each insertion step, we run two-step Monte Carlo sampling: we first randomly select the ion type and then randomly choose a position to insert the selected ion. According to eq 4, for the $n$th inserted cation, the free energy change of the whole nucleic acid-solution system can be calculated as

$$
\Delta F(n-1 \rightarrow n)=-k_{\mathrm{B}} T \ln \left[\frac{w(n)}{n}\right]+\Delta \Delta G_{\mathrm{d}}(n-1 \rightarrow n)
$$

here, $n$ could be $n_{i}$ for the species $i$ or $n_{j}$ for the species $j$. The first and second terms describe the interaction energy changes for the TB ions (in the TB region) and for the DB ions (in the DB region), respectively. Here, $\Delta \Delta G_{\mathrm{d}}(n-1 \rightarrow n)=\Delta G_{\mathrm{d}}(n)$ - $\Delta G_{\mathrm{d}}(n-1)$, where $\Delta G_{\mathrm{d}}(n)$ and $\Delta G_{\mathrm{d}}(n-1)$ are the electrostatic free energies of the DB ions with $n$ and $n-1 \mathrm{~TB}$ ions in the $\mathrm{TB}$ region, respectively (see eq $\mathrm{S} 3$ in SI). To enhance the computational efficiency, for the calculation of $\Delta \Delta G_{\mathrm{d}}$, we assume that a newly inserted $\mathrm{TB}$ ion is nonspecifically condensed to the nucleic acid; thus, $\Delta \Delta G_{\mathrm{d}}$ is a function of the number of $\mathrm{TB}$ ions. This approximation allows us to precalculate $\Delta \Delta G_{\mathrm{d}}$ to save the computational time.

We randomly select the species $i$ (or $j$ ) for the inserted TB ions according to the following probability

$$
P_{i(\text { or } j)}=\frac{\mathrm{e}^{-\Delta F\left(n_{i(\text { or } j)}-1 \rightarrow n_{i(\text { or } j)}\right)}}{\mathrm{e}^{-\Delta F\left(n_{i}-1 \rightarrow n_{i}\right)}+\mathrm{e}^{-\Delta F\left(n_{j}-1 \rightarrow n_{j}\right)}}
$$

After determining the species of the inserted ion, we randomly place the ion in the TB region according to the following probability (for ion $n$ placed at site $k$ )

$$
p_{\mathrm{f}}(n, k)=\frac{\mathrm{e}^{-\Delta U_{n}(k)}}{\sum_{k=1}^{m_{k}} \mathrm{e}^{-\Delta U_{n}(k)}}
$$

here, $U_{n}(k)$ represents the interaction energy change upon the insertion of an ion $n$ at site $k$ (see eq S2 in SI). $m_{k}$ is the number of available (vacant) sites in the M11 and M12 TB regions for monovalent cations and in the M12 and M22 regions for divalent cations. Based on eqs 5-7, we insert the $\mathrm{TB}$ ions one by one until the $\mathrm{TB}$ region is saturated. In fact, the maximum number of the TB ions $N_{\max }^{i}$ for species $i$ and $N_{\text {max }}^{j}$ for species $j$ is determined by the total charge limitation (eq 3 ) and the insertion process (eqs 5-7). Here, eqs 5 and 6 determine the type of the inserted ion (species $i$ or $j$ ) and eq 7 gives the site (location) of the inserted ion. Equation 3 determines whether the insertion process should be terminated. If the total charge of the TB ions reaches the maximum saturated value $\left(2 N_{\mathrm{p}}\right.$ with $N_{\mathrm{p}}$ as the number of nucleotides), the insertion process is terminated and the subsequent deletion process is started.

In the above insertion process, as a new TB ion is inserted, the pre-existing TB ions cannot adjust their distribution. To allow the ions to redistribute, we re-sample the ion distribution by randomly removing ions one by one such that higherenergy ions have a higher probability to be removed. Specifically, the probability for removing ion $n^{\prime}$ (at site $k$ ) from an $n$-TB ion system is determined by the energy change $\Delta U_{n^{\prime}}(k)$ for the process

$$
p_{\mathrm{d}}\left(n^{\prime}\right)=\frac{\mathrm{e}^{\Delta U_{n^{\prime}}(k)}}{\sum_{n^{\prime}=1}^{n} \mathrm{e}^{\Delta U_{n^{\prime}}(k)}}
$$

From the $(n-1)$-TB ion distributions generated in the above deletion procedure, we compute the statistical weight $w(n)$ using eq S1 in SI. We note that unlike the original MCTBI model, the current gMCTBI model considers the sampling of both monovalent and multivalent $\mathrm{TB}$ ions through an extra sampling process, namely, the random sampling of the ion 
species for the ions to be inserted (or deleted) based on eqs 5 and 6 .

\section{ASSOCIATED CONTENT}

\section{S Supporting Information}

The Supporting Information is available free of charge on the ACS Publications website at DOI: 10.1021/acsomega.9b01689.

Original MCTBI model; separate statistic weight; electrostatic free energy for DB ions; prediction quantities from the gMCTBI model (excess/depletion number of ions, linear density of ions, and average and most probabilities of TB ions); and linear densities of TB $\mathrm{Na}^{+}, \mathrm{DB} \mathrm{Na}{ }^{+}$, and all bound ions around the DNA helix in the solution with single salt (PDF)

\section{AUTHOR INFORMATION}

\section{Corresponding Author}

*E-mail: chenshi@missouri.edu.

\section{ORCID $\odot$}

Shi-Jie Chen: 0000-0002-8093-7244

\section{Notes}

The authors declare no competing financial interest.

\section{ACKNOWLEDGMENTS}

This research was supported by NIH grants R01-GM117059 and R01-GM063732 (to S.-J.C.) and the National Natural Science Foundation of China (NSFC) under Grant No. 11704333 (to L.-Z.S.).

\section{REFERENCES}

(1) Brion, P.; Westhof, E. Hierarchy and dynamics of RNA folding. Annu. Rev. Biophys. Biomol. Struct. 1997, 26, 113-137.

(2) Tinoco, I., Jr.; Bustamante, C. How RNA folds. J. Mol. Biol. 1999, 293, 271-281.

(3) Li, P. T. X.; Vieregg, J.; Tinoco, I., Jr How RNA unfolds and refolds. Annu. Rev. Biochem. 2008, 77, 77-100.

(4) Qiu, X.; Andresen, K.; Lamb, J. S.; Kwok, L. W.; Pollack, L. Abrupt transition from a free, repulsive to a condensed, attractive DNA phase,induced by multivalent polyamine cations. Phys. Rev. Lett. 2008, 101, No. 228101.

(5) Qiu, X.; Parsegian, V. A.; Rau, D. C.Divalent counterion-induced condensation of triple-strand DNA. Proc. Natl. Acad. Sci. U. S. A. 2010, 107, 21482-21486.

(6) Bloomfield, V. A. DNA condensation by multivalent cations. Biopolymers 1997, 44, 269-282.

(7) Fürtig, B.; Wenter, P.; Pitsch, S.; Schwalbe, H. Probing mechanism and transition state of RNA refolding. ACS Chem. Biol. 2010, 5, 753-756.

(8) Lilley, D. M. The origins of RNA catalysis in ribozymes. Trends Biochem. Sci. 2003, 28, 495-501.

(9) Bobyr, E.; Lassila, J. K.; Wiersma-Koch, H. I.; Fenn, T. D.; Lee, J. J.; Nikolic-Hughes, I.; Hodgson, K. O.; Rees, D. C.; Hedman, B.; Herschlag, D. High-resolution analysis of $\mathrm{Zn}(2+)$ coordination in the alkaline phosphatasesuperfamily by EXAFS and x-ray crystallography. J. Mol. Biol. 2012, 415, 102-107.

(10) Kellerman, D. L.; York, D. M.; Piccirilli, J. A.; Harris, M. E. Altered (transition) states: mechanisms of solution and enzymecatalyzed RNA 2=O-transphosphorylation. Curr. Opin. Chem. Biol. 2014, $21,96-102$

(11) Ando, T.; Tanaka, T.; Kikuchi, Y. Substrate shape specificity of $\mathrm{E}$ coli RNase $\mathrm{P}$ ribozyme isdependent on the concentration of magnesium ion. J. Biochem. 2003, 133, 445-451.
(12) Forconi, M.; Herschlag, D. Metal ion-based RNA cleavage as a structural probe. Methods Enzymol. 2009, 468, 91-106.

(13) Davis, J. H.; Foster, T. R.; Tonelli, M.; Butcher, S. E. Role of metal ions in the tetraloop-receptor complex as analyzed by NMR. RNA 2006, 13, 76-86.

(14) Cate, J. H.; Doudna, J. A. Metal-binding sites in the major groove of a large ribozyme domain. Sturcture 1996, 15, 1221-1229.

(15) Draper, D. E.; Grilley, D.; Soto, A. M. Ions and RNA folding. Annu. Rev. Biophys. Biomol. Struct. 2005, 34, 221-243.

(16) Misra, V. K.; Draper, D. E. A thermodynamic framework for $\mathrm{Mg} 2+$ binding to RNA. Proc. Natl. Acad. Sci. U.S.A. 2001, 98, 1245612461.

(17) Bai, Y.; Greenfeld, M.; Herschlag, D.; et al. Quantitative and comprehensive decomposition of the ion atmosphere around nucleic acids. J. Am. Chem. Soc. 2007, 129, 14981-14988.

(18) Bai, Y.; Chu, V. B.; Lipfert, J.; Pande, V. S.; Herschlag, D.; Doniach, S. Critical assessment of nucleic acid electrostatics via experimentaland computational investigation of an unfolded state ensemble. J. Am. Chem. Soc. 2008, 130, 12334-12341.

(19) Gebala, M.; Giambaşu, G. M.; Lipfert, J.; Bisaria, N.; Bonilla, S.; Li, G.; York, D. M.; Herschlag, D. Cation-Anion Interactions within the Nucleic Acid Ion Atmosphere Revealed by Ion Counting. J. Am. Chem. Soc. 2015, 137, 14705-14715.

(20) Draper, D. E. RNA folding: thermodynamic and molecular descriptions of the roles of ions. Biophys. J. 2008, 95, 5489-5495.

(21) Serganov, A.; Yuan, Y. R.; Pikovskaya, O.; Polonskaia, A.; Malinina, L.; Phan, A. T.; Hobartner, C.; Micura, R.; Breaker, R. R.; Patel, D. J. Structural basis for discriminative regulation of gene expressionby adenine- and guanine-sensing mRNAs. Chem. Biol. 2004, 11, 1729-1741.

(22) Serganov, A.; Huang, L.; Patel, D. J. Structural insights into amino acid binding and gene control by a lysine riboswitch. Nature 2008, 455, 1263-1267.

(23) Drozdzal, P.; Gilski, M.; Jaskolski, M. Ultra high-resolution centrosymmetric crystal structure of Z-DNA reveals the massivepresence of alternate conformations. Acta Crystallogr., Sect. D: Struct. Biol. 2016, 72, 1203-1211.

(24) Philips, A.; Milanowska, K.; Lach, G.; Boniecki, M.; Rother, K.; Bujnicki, J. M. MetalionRNA: computational predictor of metalbinding sites in RNA structures. Bioinformatics 2012, 28, 198-205.

(25) Pabit, S. A.; Meisburger, S. P.; Li, L.; Blose, J. M.; Jones, C. D.; Pollack, L. Counting ions around DNA with anomalous small-angle X-ray scattering. J. Am. Chem. Soc. 2010, 132, 16334-16336.

(26) Das, R.; Travers, K. J.; Bai, Y.; Herschlag, D. Determining the $\mathrm{Mg} 2+$ stoichiometry for folding an RNA metal ion core. J. Am. Chem. Soc. 2005, 127, 8272-8273.

(27) Soto, A. M.; Misra, V.; Draper, D. E. Tertiary structure of an RNA pseudoknot is stabilized by diffuse $\mathrm{Mg} 2+$ ions. Biochemistry 2007, 46, 2973-2983.

(28) Leipply, D.; Draper, D. E. Effects of $\mathrm{Mg} 2+$ on the free energy landscape for folding a purine riboswitch RNA. Biochemistry 2011, 50, 2790-2799.

(29) Leipply, D.; Draper, D. E. Evidence for a thermodynamically distinct $\mathrm{Mg} 2+$ ion associated withformation of an RNA tertiary structure. J. Am. Chem. Soc. 2011, 133, 13397-13405.

(30) Sun, L. Z.; Zhang, D.; Chen, S. J. Theory and modeling of RNA structure and interactions with metal ions and small molecules. Annu. Rev. Biophys. 2017, 46, 227-246.

(31) Manning, G. S. The molecular theory of polyelectrolyte solutions with applications tothe electrostatic properties of polynucleotides. Q. Rev. Biophys. 1978, 11, 179-249.

(32) Herlman-Miller, S. L.; Thirumalai, D.; Woodson, S. A. Role of counterion condensation in folding of the Tetrahymenaribozyme. I. Equilibrium stabilization by cations. J. Mol. Biol. 2001, 306, 11571166.

(33) Cherstvy, A. G. DNA cyclization: suppression or enhancement by electrostatic repulsions? J. Phys. Chem. B 2011, 115, 4286-4294. 
(34) Zhou, H.-X. Macromolecular electrostatic energy within the nonlinear Poisson-Boltzmann equation. J. Chem. Phys. 1994, 100, $3152-3162$.

(35) Misra, V.; Draper, D. E. The interpretation of $\mathrm{Mg} 2+$ binding isotherms for nucleic acids using Poisson-Boltzmann theory. J. Mol. Biol. 1999, 17, 1135-1147.

(36) Baker, N. A.; Sept, D.; McCammon, J. A.; et al. Electrostatics of nanosystems: application to microtubules and the ribosome. Proc. Natl. Acad. Sci. U.S.A. 2001, 98, 10037-10041.

(37) Baker, N. A. Improving implicit solvent simulations: A Poissoncentric view. Curr. Opin. Struct. Biol. 2005, 15, 137-143.

(38) Tjong, H.; Zhou, H.-X. The dependence of electrostatic solvation energy on dielectric constantsin Poisson-Boltzmann calculations. J. Chem. Phys. 2006, 125, No. 206101.

(39) Tjong, H.; Zhou, H.-X. GBr6NL: a generalized Born method for accurately reproducingsolvation energy of the nonlinear PoissonBoltzmann equation. J. Chem. Phys. 2007, 126, No. 195102.

(40) Xiao, L.; Wang, C.; Luo, R. Recent progress in adapting Poisson-Boltzmann methods to molecular simulations. J. Theory Comput. Chem. 2014, 13, No. 1430001.

(41) Koculi, E.; Lee, N.-K.; Thirumalai, D.; Woodson, S. A. Folding of the Tetrahymena ribozyme by polyamines: importance of counterionvalence and size. J. Mol. Biol. 2004, 341, 27-36.

(42) Tan, Z. J.; Chen, S. J. Electrostatic correlations and fluctuations for ionbinding to a finite length polyelectrolyte. J. Chem. Phys. 2005, 122, No. 044903.

(43) Hayes, R. L.; Noel, J. K.; Whitford, P. C.; Mohanty, U.; Sanbonmatsu, K. Y.; Onuchic, J. N. Reduced model captures Mg2+RNA interaction free energy of riboswitches. Biophys. J. 2014, 106, $1508-1519$.

(44) Cheatham, T. E., III; Case, D. A. Twenty-five years of nucleic acid simulation. Biopolymers 2013, 99, 969-977.

(45) Hayes, R. L.; Noel, J. K.; Mohanty, U.; Whitford, P. C.; Hennelly, S. P.; Onuchic, J. N.; Sanbonmatsu, K. Y. Magnesium fluctuations modulate RNA dynamics in the SAM-I riboswitch. J. Am. Chem. Soc. 2012, 134, 12043-12053.

(46) Auffinger, P.; Bielecki, L.; Westhof, E. The Mg2+ binding sites of the 5S rRNA loop E motif as investigatedby molecular dynamics simulations. Chem. Biol. 2003, 10, 551-561.

(47) Denesyuk, N. A.; Thirumalai, D. How do metal ions direct ribozyme folding? Nat. Chem. 2015, 7, 793-801.

(48) Mak, C. H.; Henke, P. S. Ions and RNAs: free energies of counterion-mediated RNA fold stabilities. J. Chem. Theory Comput. 2013, 9, 621-639.

(49) Henke, P. S.; Mak, C. H. Free energy of RNA.counterion interactions in a tight-binding modelcomputed by a discrete space mapping. J. Chem. Phys. 2014, 141, No. 064116.

(50) Ovanesyan, Z.; Medasani, B.; Fenley, M. O.; Guerrero-Garcia, G. I.; de la Cruz, M. O.; Marucho, M. Excluded volume and ion-ion correlation effects on the ionic atmosphere around B-DNA:Theory, simulations, and experiments. J. Chem. Phys. 2014, 141, No. 225103.

(51) Borukhov, I.; Andelman, D.; Orland, H. Steric effects in electrolytes: a modified Poisson-Boltzmann equation. Phys. Rev. Lett. 1997, 79, 435-438.

(52) Chu, V.; Bai, Y.; Lipfert, J.; Herschlag, D.; Doniach, S. Evaluation of ion binding to DNA duplexesusing a size-modified Poisson-Boltzmann theory. Biophys. J. 2007, 93, 3202-3209.

(53) Andresen, K.; Das, R.; Park, H.; Smith, H.; Kwok, L.; Lamb, J.; Kirkland, E.; Herschlag, D.; Finkelstein, K.; Pollack, L. Spatial distribution of competing ions around DNA in solution. Phys. Rev. Lett. 2004, 93, No. 248103.

(54) Hayes, R. L.; Noel, J. K.; Mandic, A.; Whitford, P. C.; Sanbonmatsu, K. Y.; Mohanty, U.; Onuchic, J. N. Generalized manning condensation model captures the RNA ion atmosphere. Phys. Rev. Lett. 2013, 114, No. 258105.

(55) Gebala, M.; Bonilla, S.; Bisaria, N.; Herschlag, D. Does cation size affect occupancy and electrostatic screening of the nucleicacid ion atmosphere? J. Am. Chem. Soc. 2016, 138, 10925-10934.
(56) Meisburger, S. P.; Pabit, S. A.; Pollack, L. Determining the locations of ions and water around DNAfrom X-ray scattering measurements. Biophys. J. 2015, 108, 2886-2895.

(57) Krasovska, M. V.; Sefcikova, J.; Sponer, J. Cations and hydration in catalytic RNA:molecular dynamics of the hepatitis delta virus ribozyme. Biophys. J. 2006, 91, 626-638.

(58) Chen, A. A.; Draper, D. E.; Pappu, R. V. Molecular simulation studies of monovalent counterion-mediatedinteractions in a model RNA kissing loop. J. Mol. Biol. 2009, 390, 805-819.

(59) Chen, A. A.; Marucho, M.; Baker, N. A.; Pappu, R. Simulations of RNA Interactions with Monovalent Ions. Methods Enzymol. 2009, 469, 411-432.

(60) Dong, F.; Olsen, B.; Baker, N. A. Computational methods for biomolecular electrostatics. Methods Cell Biol. 2008, 84, 843-870.

(61) Giambaşu, G. M.; Luchko, T.; Herschlag, D.; York, D. M.; Case, D. A. Ion counting from explicit-solvent simulations and 3DRISM. Biophys. J. 2014, 106, 883-894.

(62) Giambaşu, G. M.; Gebala, M. K.; Panteva, M. T.; Luchko, T.; Case, D. A.; York, D. M. Competitive interaction of monovalent cations with DNA from 3D-RISM. Nucleic Acids Res. 2015, 43, 84058415.

(63) Tan, Z. J.; Chen, S. J. Ion-mediated nucleic acid helix-helix interactions. Biophys. J. 2006, 91, 518-536.

(64) Tan, Z. J.; Chen, S. J. Electrostatic free energy landscape for nucleic acid helix assembly. Nucleic Acids Res. 2006, 34, 6629-6639.

(65) Tan, Z. J.; Chen, S. J. RNA helix stability in mixed Na+/Mg2+ solution. Biophys. J. 2007, 92, 3615-3632.

(66) Tan, Z. J.; Chen, S. J. Salt dependence of nucleic acid hairpin stability. Biophys. J. 2008, 95, 738-752.

(67) Tan, Z. J.; Chen, S. J. Predicting ion binding properties for RNA tertiary structures. Biophys. J. 2010, 99, 1-12.

(68) He, Z.; Chen, S. J. Predicting ion-nucleic acid interactions by energy landscape-guided sampling. J. Chem. Theory Comput. 2012, 8, 2095-2102.

(69) He, Z. J.; Chen, S. J. Quantifying coulombic and solvent polarization-mediated forces between DNA helices. J. Phys. Chem. B 2013, 117, 7221-7227.

(70) Zhu, Y.; Chen, S. J. Many-body effect in ion binding to RNA. J. Chem. Phys. 2014, 141, No. 055101.

(71) Zhu, Y. H.; He, Z. J.; Chen, S. J. TBI server: a web server for predicting ion effects in RNA folding. PLoS One 2015, 10, No. e0119705.

(72) Sun, L. Z.; Chen, S. J. Monte Carlo Tightly Bound Ion Model:Predicting Ion-Binding Properties of RNA with Ion Correlations and Fluctuations. J. Chem. Theory Comput. 2016, 12, 3370-3381.

(73) Sun, L. Z.; Zhang, J. X.; Chen, S. J. MCTBI: a web server for predicting metal ion effects in RNA structures. RNA 2017, 23, 11551165.

(74) Lipfert, J.; Doniach, S.; Das, R.; Herschlag, D. Understanding nucleic acid-Ion Interaction. Annu. Rev. Biochem. 2014, 83, 813-841.

(75) Nguyen, T. T.; Grosberg, A. Y.; Shklovskii, B. I. Macroions in Salty Water with Multivalent Ions: Giant Inversion of Charge. Phys. Rev. Lett. 2000, 85, 1568-1571.

(76) Lenz, O.; Holm, C. Simulation of charge reversal in salty environments: Giant overcharging? Eur. Phys. J. E 2008, 26, 191-195.

(77) Jordan, E.; Roosen-Runge, F.; Leibfarth, S.; Zhang, F.; Sztucki, M.; Hildebrandt, A.; Kohlbacher, O.; Schreiber, F. Competing Salt Effects on Phase Behavior of Protein Solutions:Tailoring of Protein Interactionby the Binding of Multivalent Ions and Charge Screening. J. Phys. Chem. B 2014, 118, 11365-11374.

(78) Romer, R.; Hach, R. tRNA conformation and magnesium binding. A study of a yeastphenylalanine-specific tRNA by a fluorescent indicator and differential melting curves. Eur. J. Biochem. 1975, 55, 271-284.

(79) Lu, X. J.; Olson, W. K. 3DNA: a software package for the analysis, rebuilding and visualization of three-dimensionalnucleic acid structures. Nucleic Acids Res. 2003, 31, C5108-C5121. 
(80) Berman, H. M.; Westbrook, J. D.; Feng, Z.; Gilliland, G. L.; Bhat, T. N.; Weissig, H.; Shindyalov, I. N.; Bourne, P. E. The protein data bank. Nucleic Acids Res. 2000, 28, 235-242.

(81) Westhof, E.; Sundaralingam, M. Restrained refinement of the monoclinic form of yeast phenylalanine transfer RNA.Temperature factors and dynamics, coordinated waters, and base-pair propeller twist angles. Biochemistry 1986, 25, 4868-4878.

(82) Pavlov, M.; Siegbahn, P. E. M.; Sandstrom, M. Hydration of beryllium, magnesium, calcium, and zinc ions using densityfunctional theory. J. Phys. Chem. A 1998, 102, 219-228.

(83) Markham, G. D.; Glusker, J. P.; Bock, C. W. The arrangement of first- and second- sphere water molecules indivalent magnesium complexes: results from molecular orbitaland density functional theory and from structural crystallography. J. Phys. Chem. B 2002, 106, $5118-5134$.

(84) VDW Radii. https://www.cgl.ucsf.edu/chimerax/docs/user/ radii.html.

(85) Meng, S.; Chakarov, D. V.; Kasemo, B.; Gao, S. Twodimensional hydration shells of alkali metal ions at a hydrophobic surface. J. Chem. Phys. 2004, 121, 12572-12576.

(86) Mähler, J.; Persson, I. A Study of the Hydration of the Alkali Metal Ions in Aqueous Solution. Inorg. Chem. 2012, 51, 425-438.

(87) Garcìa-Tarrès, L.; Guárdia, E. Hydration and Dynamics of a Tetramethylammonium Ion in Water:A Computer Simulation Study. J. Phys. Chem. B 1998, 102, 7448-7454.

(88) Rouzina, I.; Bloomfield, V. A. Competitive electrostatic binding of charged ligands to polyelectrolytes:practical approach using the non-linear Poisson-Boltzmann equation. Biophys. Chem. 1997, 64, 139-155. 